\title{
Taking Scripts as a Model of Lesson Organisation for the Integration of Culture and Language in ELT
}

\author{
Raquel Criado \\ University of Murcia \\ rcriado@um.es
}

\begin{abstract}
Culture and language are two intertwined constructs essential to understand the interpretation of reality by different communities. Apprehending the foreign language culture is thus vital to attain genuine and fully communicative competence in the L2. This article specifically focuses on the teaching of scripts in ELT. Scripts (Shank and Abelson, 1977) are defined as proceduralised sequences of events of a temporal, cause-and-effect nature which underlie daily stereotyped situations. In this work, scripts are also regarded as cognitive sequences of events for culturally idiosyncratic situations pertaining to a certain linguistic population. The objective of this article is to propose the integration of culture and language teaching in ELT by means of the pedagogical adaptation of scripts for cultural situations made up of an ordered sequence of events. This will be accomplished through the "Communicative Processes-based model of activity sequencing" (CPM). The present proposal attempts at compensating the shortage of traditional culture teaching, which has been almost exclusively restricted to lexis or Elementary Meaning Units (Lado, 1957). The CPM adaptation will be illustrated with a complete ELT lesson created by the author for the script of the Cheese-Rolling festival in the English region of Cotswolds. This lesson will be critically analysed from cultural, pedagogical and cognitive perspectives.
\end{abstract}

\section{Culture and language}

Language may be defined as a set of common sounds and symbols used by individuals within a group to communicate with each other. Anthropologists, on their side, refer to culture as a set of shared values, beliefs, expectations, customs, jargon, and rituals. At a first sight, both 
concepts may appear as well delimited and different in nature. However, relationships between language and culture have lately been a recurrent topic of research and scientific discussions. Sometime earlier, Sapir (1958 [1929]) and Whorf(1956) called attention on how the language, any language, shapes and models the way we perceive the world, as shown in the conceptualisation and categorisation of reality detected in people's native language or transmitted through it. Moreover, they also remind us that idiosyncratic cultural elements explain many differences among languages, or that concepts coined in one language and not in other languages are due to cultural differences. Sapir's and Whorf's ideas account for the fact that speakers of a specific language are often blind to other views of the world, precisely those connected to or derived from other languages and used by other linguistic communities. In Sapir's words (1958: 69):

It is quite an illusion to imagine that one adjusts to reality essentially without the use of language and that language is merely an incidental means of solving specific problems of communication or reflection. The fact of the matter is that the 'real world' is to a large extent unconsciously built upon the language habits of the group. No two languages are ever sufficiently similar to be considered as representing the same social reality. The worlds in which different societies live are distinct worlds, not merely the same world with different labels attached... We see and hear and otherwise experience very largely as we do because the language habits of our community predispose certain choices of interpretation.

Whorf, his disciple, is still more precise when he states (Whorf, 1956:214):

We cut nature up, organize it into concepts, and ascribe significances as we do, largely because we are parties to an agreement to organize it in this way - an agreement that holds throughout our speech community and is codified in the patterns of our language.

Whorf's hypothesis explains why monolinguals tend to be also monocultural, because every linguistic community 'cuts' reality in only one way, which will not necessarily coincide with the kind of reality 'cut' by other linguistic communities. Every language in fact opens a new perspective on the world around us and so it becomes like a mirror of what people think, of their beliefs, their convictions, and in general, of their ideas on the environment. Learning how people think and feel about their environment and how they categorise things around them provides relevant and decisive information on their way of life, on what their interests and values are. From that point of view, language and culture can be considered real tools for identifying reality as categorised and interpreted by human beings.

The categorisation we have of a specific environment will always be used as a means for the interpretation of any other environment we may face. Visitors of other cultures will interpret them in terms of their own culture. Or this will be at least the first approach to other cultures, unless we make an effort and try to investigate first whether the categories underlying the cultures of other groups are the same as ours or not. Even if we succeed in this, the filter of our own culture and language will still be there and will often interfere with other cultures and languages. This fact cements subjective and different views of the same thing and favours misunderstanding and conflicts. 


\section{Language, thought and culture}

If we conceptualise and encapsulate reality through language, language will also frame the cultural values we built inside our minds, at least in so far as language will always constraint the expression of those cultural elements. The names assigned to concepts will function as the usual vehicles to transmit the meaning attached to them. If this is true, it is also to be taken for granted that language will be used for transmitting cultural elements. In a similar way, it could be stated too that the culture of a speaking community has also been the base on which concepts have been built and categories have been organised. In any way we look at it, culture and language appear as closely interrelated and interdependent. This brings with the need for taking culture into consideration when dealing with language in general or with the teaching of language in particular.

Language and culture are not to be taken as the same reality, however. Even though linguistic determinism (i.e., thought is fully determined by language; there is no thought without language) is an extreme outcome of Sapir's hypothesis, linguistic relativity (different languages are representative of different views on the world, and therefore there is variation in thought and languages) is well rooted in linguistic reality (there are different languages, and different perceptions (thought) of the world). A more universalistic approach to language and thought claims quite a different understanding of the nature of language in relation to thought: that language is a kind of a dress of our thought. This view asserts that the same ideas may be expressed in many different ways and in many different languages. What varies is not the content but rather the way of externalising and making it accessible to others (through language). This would fit Popper's statement that "even totally different languages are not untranslatable" (Popper, 1970: 56), but it would be more problematic within the Whorfian hypothesis, which assumes a more deterministic link between thought and language; so much so that translation between languages may become impossible. Translatability and/or transportability of thought are certainly a relevant issue in this respect, but are not at the centre of our argument here.

A moderate stand on the issue may support the hypothesis that language and culture are relative constructs and two distinct components, even though they are closely related to each other and interdependent. Traditional linguistic theories have not always helped in transmitting the idea of this mutual dependency and connectivity. Instead, they have contributed to think of language as an autonomous formal system, complete in its own, heavily and fully governed by logic. Logic is no doubt a key component in the organisation of language as a system. But insofar as language encompasses cultural and pragmatic elements and is built on them, it is pervaded by ingredients outside the formal linguistic system, which may even act as distorting elements of such a logical system. Language in fact - within a universalistic theory - can be considered a partial sub-construct of culture, this being a complex body in itself resulting from the melting together of various and somehow heterogeneous ingredients. The ingredients of culture and language are not totally the same, but all of them are headed in the same direction and cooperate to reach a final and shared goal: the building of a complex system of ideas and symbols representative of reality and proceduralised in specific beliefs and ways of life. Such a system is efficient for receiving and 
transmitting information to or from individuals within the group; in doing so, the system strengthens, grows and expands. The information transmitted is vital for the survival of the group and includes data which all the members need to know in order to interact among them suitably.

Linguistic systems are based on codes governed by rules or patterns which must be previously known by the speaker and the recipient. We know that linguistic codes are complex in nature: in the process of codification and decodification both speaker and receiver have to take decisions and options in order to avoid ambiguity in the message. This decision-taking process does not only depend on the rules derived from explicit or implicit formal logic, but also on other accompanying elements, such as who the receiver is, where the message is transmitted, which concepts are more likely to be suggested by the words used, or which will be the expected interpretation and understanding of the words used on the side of the potential recipient. Context of a non-linguistic nature will play a key role in the shaping of the message as a whole.

Culture in its turn is governed by a code too. Such a code allows the individuals within a group to attach the same or similar values to specific elements, specific gestures, specific facts and actions, etc. For that reason, a particular way of dressing, a particular tradition or a specific colour is assigned a specific meaning or attached to specific feelings. All the members of the group will interpret these events or facts in the same way. Simultaneously, those facts and events and the associations they are linked to will frame their minds, the repetitive access to such associations will make the group members proceduralise their conceptualisation and will ultimately condition their interpretation of reality.

Dependency on a code is a feature shared by language and culture. The code is different and of a different nature, but in both cases it is built on a limited and arbitrary set of links and associations created by each linguistic community in order to share the same or a similar interpretation of the outside world.

\section{Words and culture}

The association of culture and language in the field of language teaching has often centred on the cultural content of words or lexical units. Lado (1957) was a pioneer in bringing cultural awareness to the field of language teaching, and he offered in this respect examples based on words with contrasting or un-paired meanings in two or more different languages. His method looked for Elementary Meaning Units (EMU) associated with linguistic units (words or phrases), which were applied in the Audiolingual Method. Some examples of Lado's EMUs are as follows. 'Leg' in English has not a fully equivalent term in Spanish. Spanish speakers use pierna when referred to human beings, but pata when referred to animals (which implies a different 'cut' or conceptualisation of reality by English and Spanish speakers). 'Wine' has different connotations - hence, partially different meanings - in Spain, Sweden or Iran, etc. Those and many other similar cases illustrate the way specific communities of speakers organise or perceive reality, which is later externalised through linguistic forms. In Lado's model, EMUs must firstly be identified, and then they can also be taught. The consideration 
of cultural items as EMUs is not free from limitations and problems. Among other things, EMUs are supposed to be discrete items, while cultural elements are not always easily reduced to well defined constructs, since they often appear as a part of a continuum with its pieces heavily intertwined and connected with each other. On the other hand, this cultural analysis, as any kind of analysis, is always connected to the isolation of discrete elements from which more global knowledge is often reached. Is it possible to apply a similar procedure to dealing with culture and language?

The association of EMUs to words would imply serious limitations in the interpretation of culture as well. Some scholars (Nagy and Scott, 2000; Gardner, 2007; Sánchez, 2007, among others) remind us of the difficulty it entails to specify exactly what a word is and what it means to know a word. Enclosing culture within words is therefore a risky task. To begin with, many words have more than one meaning, but only one is selected in discourse. As a result, the use of polysemous words would not be possible outside the context they belong to, since it is the context and the situation that triggers or 'activates' the right meaning (among several possible meanings). By 'situation' I mean here a setting with elements beyond the formal linguistic system, including what we generically call culture.

Let us illustrate the point above. The meaning of 'has' in "Peter has a book on his desk" is not the same as in "Peter has tea at Mary's house". If the linguistic form - 'has' - is the same and the syntax of both sentences is similar, the reason for the semantic difference of the word can only derive from co-text and context. The nature of 'book' (an object with a specific function: reading) and 'tea' (a drink) is decisive for defining the meaning of 'has'. Basic knowledge about the nature of 'book' and 'tea' and their functions in the real world of the speakers are deeply embedded in their cultural behaviour, or in the culture of particular countries (i.e. groups of people sharing the same language and used to 'having tea'). That is, you cannot separate the meaning of 'has' in these sentences from the conceptualisation of the objects or things involved in the linguistic forms used, or from the cultural setting within which they are used. The need for extralinguistic context and situational background is still more urgent if words alone and in isolation do not suffice to build a message. In addition to that, cultural features are often based on larger semantic fields, far beyond the word boundaries and closer to what we usually call 'situation'. A situation is typically a construct based on a simple or complex sequence of events that implies words and sentences, but is not limited to these minimal linguistic units. This point will be reconsidered in section 5 .

\section{Teaching language and culture}

We can probably state that human nature is not independent of culture, at least in the sense that culture belongs to the nature of human beings. Hence we must conclude that studying a foreign language carries with it the study of the nature of other people, or that studying a foreign language cannot be dissociated from the study of its culture (McDevitt, 2004). This is what many authors claim nowadays and what the Communicative Language Teaching has promoted since the late seventies (Byram, 1989, 1997; Kramsch, 1993, 1998, 2001; Byram et al., 1994). The Common European Framework (CEFR) (2001) is very clear in this respect: 
"The learner [of a second or foreign language and culture] does not simply acquire two distinct, unrelated ways of acting and communicating. The language learner becomes plurilingual and develops interculturality" (p. 11).

As a consequence, the teaching of culture in the foreign language classroom is widely accepted and there is a significant shift away from form and structure in favour of multiculturalism and the plurality of approaches, which includes plurality of cultures and ways of looking at the world. Teachers have become more conscious of the seamless relationship between culture and language, or among culture, language and society. From this perspective, it would be difficult to understand the study of a foreign language separated from the culture of the community of its native speakers. It must also be emphasised that culture is not limited to the 'fine arts and literature' (Culture, with capital C). The kind of culture I refer to here encompasses all aspects in the way of life of a group of people sharing similar values, beliefs, expectations, habits, etc. To the list of competences habitually dealt with in language teaching, a new competence must be added: the cultural 'competence'. In other words, teachers should supply intercultural teaching in their classes (Kramsch, 2001; Sánchez, personal communication).

The main problem in teaching the 'cultural competence' is to define its content and, from the point of view of language teachers, how to teach it. Literature on the issue abounds in examples of cultural elements connected to specific lexical items or situations. But we are still far from having a syllabus of cultural elements suitably integrated with the language that must be taught. The pioneering work by Lado mentioned above could lead to interesting and useful conclusions, but much work still lies ahead. The CEFR (2001) abounds in references to language and culture (culture is mentioned 35 times). Moreover, it specifies sociocultural knowledge and intercultural awareness as two types of declarative knowledge within the 'general competences' that the L2 learners must acquire - besides the 'communicative language competences'. Sociocultural knowledge relates to "knowledge of the society and culture of the community or communities in which a language is spoken [...]" $(C E F R, 2001$ : 102). A warning is added as it is likely to lie outside the learner's previous experience and, therefore, it may be distorted by stereotypes. On the other hand, intercultural awareness represents "Knowledge, awareness and understanding of the relation (similarities and distinctive differences) between the 'world of origin' and the 'world of the target community' " (CEFR, 2001: 103). Accordingly, it embraces an awareness of the existence of national stereotypes and the related necessity to avoid accepting them without any question at all. Sociocultural knowledge, then, should desirably be refined by intercultural awareness.

The $C E F R$ even provides a reasonably exhaustive list of the "features distinctively characteristic of a particular European society and its culture": everyday living, living conditions, interpersonal relations (including relations of power and solidarity), values, beliefs and attitudes, body language, social conventions and ritual behaviour. The following is the detailed list for the third feature (interpersonal relations). See pp. 102-103 in the CEFR for the full list of all the features. 
3. Interpersonal relations (including relations of power and solidarity) e.g. with respect to:

- class structure of society and relations between classes;

- relations between sexes (gender, intimacy);

- family structures and relations;

- relations between generations;

- relations in work situations;

- relations between public and police, officials, etc.;

- race and community relations;

- relations among political and religious groupings.

To the list above we could add other types of cultural elements highlighted by Kramsch (2001), and which are also subject to belong to the cultural syllabus: paralanguage (pitch, rhythm and intonation), the use of time (chronemics) and the use of space (proxemics).

It should be observed that despite this emphasis on the need to apprehend the foreign language culture and to become interculturally aware, the $C E F R$ does not provide any directions on how to teach cultural elements. It is true that after reading the CEFR one might induce that any language seems to be embedded within a specific culture as one of its ingredients; nevertheless, the reader of the CEFR ends up with the feeling that culture is rather considered and presented as an extralinguistic component, including the above-mentioned beliefs, gestures, habits, etc. But language and culture share many aspects, particularly in the conceptualisation and categorisation of the world. The ideal teacher should be conscious of such a reality in order to find out suitable ways to present the foreign language in connection to the understanding of the world encapsulated in the language being taught. This paper precisely aims to design a proposal that pursues this goal.

\section{Scripts, situations and communicative processes}

I have argued that teaching language and culture separately is not the ideal method. Thus, is there a way to integrate both components in the language classroom? The EMUs defined by Lado are an interesting way of approaching the issue and they may be useful to discover the cultural implications of words and even phrases. But as mentioned before in section 3, the EMUs outlined by Lado are rather restricted to the word level. We need to pay attention to a larger context or to larger situations as well. Culture cannot be enclosed in words alone, let alone in de-contextualized lexical items.

Context is not only relevant for word sense disambiguation in order to decide on the right meaning of polysemous words (Almela, 2006). It is also relevant for completing, defining and building cultural content. Contexts have the potential to contain and describe real life situations and are therefore more likely to illustrate events with a heavy cultural load, since they often reflect habits, ways of life or personal attitudes of the speakers or main characters. A situation that describes the patterns of Spaniards when they invite other people will necessarily imply the code, the 'protocol' and the conditions underlying invitations among the Spanish community of speakers. It is well known, for example, that in contrast to what is 
common in other cultures, Spaniards usually repeat the invitation twice or more whenever they really want to invite somebody. As a rule, a non reiterative invitation should not be taken into consideration. Our challenge is to transmit this cultural pattern while teaching Spanish for inviting people.

In this paper I specifically concentrate on those situations which imply a sequence of steps or events; however, the focus is not so much on simple daily situations - for instance, going to the cinema or booking some holidays - but rather on more complex situations idiosyncratic to certain populations such as the Spanish celebrations of the Bando de la Huerta (The Garden Festival), La Tomatina (Tomato Fight), San Fermín, or the English festivals Guy Fawkes Night, Lord Major Show, etc. I believe that the latter type of situations cover specific cultural content very relevant to the L2 culture and which needs to be explicitly dealt with in the foreign language classroom.

From a cognitive perspective, native speakers of a language have proceduralised (i.e. internalised and consolidated in their neural system) the temporal or cause-effect sequence of events or steps that a situation in a certain context is made up of. Such a cognitive sequence is called a script. Scripts were proposed by Shank and Abelson (1977) as the event version of schemata, which are abstract mental structures representative of the knowledge of the world we have in our minds or memory (Rumelhart and Ortony, 1976). Scripts are therefore standard or prototypical sequences of events or actions referred to certain situations and conveniently stored in our memory. Shank and Abelson (1977) illustrate the notion of a script with the sample situation of 'going to a restaurant'. This script involves the following ordered sequence of actions: Entering, ordering, eating and exiting. According to Anderson (2005: $165)$, scripts and schemata "can serve as valuable bases for predicting missing information and for correcting errors in the information". In this way they become very important tools for the comprehension of the outer world. They encode our background knowledge, which is formed out of our own experience or derives from what we have observed in other people's behaviour. It should be noticed that scripts tend to be socio-culturally driven (Macaro, 2003). For example, Russian table manners are different from Spain, where the following Russian procedure is not followed: toasting is very frequent and for each drinking of a toast, the fellow diners have to take a sip of vodka. From this perspective, scripts can also be extrapolated to the sequence of events or steps that constitute complex cultural units relevant to a specific community, which has proceduralised such cognitive sequences in the same way as those mentally stored for more simple situations.

My goal in this paper is to approach the teaching of language and culture in context through scripts underlying the sequence of actions or steps in complex cultural situations. As 'frames' of real communicative situations and their processes, scripts are excellent tools to reach a suitable and effective integration of language and culture in the EFL classroom. Surprisingly however, no method, not even the Communicative Language Teaching Method, has taken into consideration scripts or culture in the sense of an ensemble of events which integrate a larger cultural unit than Lado's EMUs. The model I offer here is novel and encloses a high potential for integrating the teaching of language and culture.

Of course, scripts must be pedagogically adapted in order to bring them to the classroom. This is the condition and the challenge posed by scripts as teaching tools. My adaptation 
strategy will rely on the "Communicative-Processes based model of activity sequencing" (hence CPM), as it has been described by Sánchez (2001) and Criado (2008). Real-life eventbased communicative situations or scripts which are made up of a sequence of events constitute the model for ordering all the activities in the teaching sequence. Adhering to such an order of events guarantees the fulfilment of a particular communicative situation or script. Thus all the activities are sequenced according to the logical order of events or communicative processes found in real-life communicative situations or scripts.

As a result of this essential characteristic of the CPM, there appears great variety in the multiple teaching sequences that can be devised adapting the sequence of real-life communicative situations and scripts. This might have a direct positive effect in students' attitude towards language learning. Such variety is ensured because every person does not follow an identical order of steps or processes in each communicative situation or script. For instance, in booking a holiday, a person can decide where to go by searching on the Internet, consulting a travel agent, or asking some friend or relatives, etc.

In the next section I will exemplify a CPM lesson which reflects a pedagogically adapted script.

\section{Teaching language and culture through scripts: a sample lesson model}

The script that will be used as the skeleton for a CPM-based lesson is the Cheese-Rolling festival at Cooper's Hill, in the southern-western English region of Cotswolds. It is held annually on Spring Bank Holiday (last Monday in May) and consists of several races where people chase a rolling Double Gloucester cheese by throwing themselves down Cooper's Hill. Its origins can be traced back to 200 years ago, even though some Roman and pagan antecedents have been suggested with no real evidence (http://www.answers.com/topic/cooper-s-hill-cheese-rolling-and-wake). This regional celebration is becoming more and popular, up to the point that it now has an official webpage (http://www.cheese-rolling.co.uk/index.htm) and there is even a Canadian version which started in August 2008 (http://www.canadiancheeserolling.ca/)

Two main steps are involved in the pedagogic adaptation of a script in the language classroom: a) to outline the schedule of the possible real-life sequence of events in the script (Cheese-Rolling festival) and b) to devise a CPM unit on the basis of the previous sequence. This second step firstly entails the design of a communicative situation which covers the reallife steps in a); secondly, within such a communicative situation it is necessary to indicate the stages it consists of; thirdly, the activities of the teaching sequence will be devised in correspondence with each communicative stage.

In the present case, I have opted for the following possible sequence of real actions or communicative processes underlying the Cheese-Rolling event:

1. You obtain information about the festival if you do not belong to the region.

2. You decide to go.

3. You arrive at the town where the festival is celebrated: Brockworth. 
4. You arrive where the cheeses are rolled: Cooper's Hill.

5. You climb Cooper's Hill.

6. You roll down Coopers' Hill chasing the cheese.

7. You are seen to due to the injuries provoked by the race down the mountain.

8. You tell your experience.

Evidently, not all the previous actions should compulsory appear in this script for CheeseRolling; for instance, if you belong to the Cotswold region, you do not need to inform yourself about Cheese-Rolling; what is more, maybe you decide not to roll and simply participate as a spectator. Nevertheless, the previous list does include the minimum basic steps for someone who does roll down Cooper's Hill chasing the cheese.

On the basis of the schedule above and a story at the BBC website about three friends attending the Cheese-Rolling festival (http://www.bbc.co.uk/gloucestershire/content/articl es/2008/05/22/prepare_to_roll_feature.shtml), I outlined the following specific communicative situation which encompassed the eight previous steps: Mike, a young man, hears about the Cheese-Rolling festival. He and his friend decide to attend it. They take a bus to Brockworth, go to Cooper's Hill, climb it and roll down the mountain chasing the cheese. They end up with several minor contusions. Finally, Mike tells his experience to his girlfriend. This communicative situation was transferred in the teaching sequence as five communicative stages around which the activities were designed. Table 1 includes the correspondence between the eight communicative processes in the real-life sequence outlined before and the five communicative stages in the teaching sequence. As can be observed, for the purposes of the pedagogic adaptation that will be explained below, communicative event or process number 1 in the real-life sequence is divided into 1 and 1bis, which respectively correspond to teaching stages 1 and 3 ; the second communicative action or the decision-making process is included in-between. These are normal adjustments required by the conversion of a real-life communicative situation or script into a teaching sequence in the classroom, and overall they do not distort the normal or logical sequence of real-life actions underlying scripts.

\begin{tabular}{l|l}
\hline \hline $\begin{array}{l}\text { Communicative event in the real-life } \\
\text { sequence }\end{array}$ & $\begin{array}{l}\text { Communicative stage in the teaching } \\
\text { sequence }\end{array}$ \\
\hline You obtain information about the festival if you & $\begin{array}{l}\text { Mike listens to a national radio programme } \\
\text { telling of the Cheese-Rolling festival in } \\
\text { do not belong to the region. }\end{array}$ \\
Gloucestershire.
\end{tabular}

You decide to go.

2) Mike talks to a friend and both of them decide to attend this year's Cheese-Rolling festival.

1 bis. You obtain information about the festival if you do not belong to the region.

3) After talking to his friend, Mike feels more excited about the Cheese-Rolling festival. He searches on the Internet for more information. He discovers a website about people's injuries 
when chasing the cheese down the hill. Mike talks to a friend and both of them decide to attend this year's Cheese-Rolling festival.

You arrive at the town where the festival is celebrated: Brockworth.

You arrive where the cheeses are rolled: Cooper's Hill.

4) The Spring Bank Holiday has arrived. Mike and his friend get to Brockworth by bus. Then

You climb Cooper's Hill. they reach the top of Cooper's Hill and make it to the front line to participate in one of the

You roll down Coopers' Hill chasing the cheese. Cheese-Rolling races.

You are seen to due to the injuries provoked by the race down the mountain.

You tell your experience.

5) Mike tells his girlfriend about his CheeseRolling day.

Table 1. Correspondence between the communicative event in the real-life sequence and the communicative stage in the teaching sequence.

Finally, such five communicative stages in the teaching sequence were translated as twelve activities, which include a final follow-up writing section without any correspondence with any communicative stage. This was added for the purposes of writing skill development and the consolidation of the language studied throughout the lesson.

Table 2 offers the whole content of the lesson targeted at EFL intermediate learners. The left column comprises the communicative stages and their corresponding activities appear in the right column. All the activities are my own contribution except for the grammar rules in section 4 . The aural and written texts from sections 1 and 3 have been adapted from the three following sources:

http://www.cheese-rolling.co.uk/index.htm

http://www.answers.com/topic/cooper-s-hill-cheese-rolling-and-wake

http://en.wikipedia.org/wiki/Cheese_rolling

The content of the email in sections 4 and 6 was partially inspired from bbc.co.uk/gloucestershire/content/articles/2008/05/22/prepare_to_roll_feature.shtml.

The Appendix at the end of this article includes the listening text from section 1, the body picture for exercise 3.1., the reading text from activity 3.2. and the informal email used in sections 4 and 6. 


\section{Communicative stage in Activities}

the teaching sequence

1) Mike listens to a national radio programme telling of the Cheese-Rolling festival in Gloucestershire.

2) Mike talks to a friend and both of them decide to attend this year's CheeseRolling festival.

\section{LISTENING}

1.1.) Listen to a radio programme on the Cheese-Rolling festival in Gloucestershire, England. What does it consist of? What's the prize?

1.2.) Listen again and answer these questions:

Where does it take place?

What are the origins?

What's the distance from the top to the bottom of the hill?

What does it cost to be a spectator?

What does it cost to compete?

How can you enter a race?

\section{2) FUNCTIONS: SUGGESTING AND AGREEING}

2.1.) Complete the questions and responses with one word in the box. Is the English way of suggesting and agreeing very different from your mother tongue?

Why don't we go to Cooper's Hill?

What about going to Cooper's Hill?

Let's go to Cooper's Hill.

Shall we go to Cooper's Hill?

Why not go to Cooper's Hill?

$\begin{array}{lll}\text { Yes, let's. } & \text { Yes, why not? } & \text { (That's a) good idea. } \\ \text { All right. } & \text { OK. } & \text { Fine. }\end{array}$

2.2.) Practise with your partner. Imagine you are friends. A invites $B$ to go to the following places, and B agrees. Change roles.

Library, cinema, gym, bookshop, pub, another friend's house for coffee.

3) After talking to his friend, Mike feels more excited about the Cheese-Rolling festival. He searches on the Internet for more information. He discovers a website about people's injuries when chasing the cheese down the hill.

\section{3) VOCABULARY AND READING}

3.1.) Vocabulary: Imagine you participate in the cheese race. Which parts of your body would you seriously harm? Write the name of each body part in its corresponding box. How do you pronounce them?

ankle arm belly breast chin ear elbow eyebrows eyes
face foot hand head knee leg mouth nose shoulder
stomach teeth


3.2.) Read the following extract from the Cheese-Rolling website (http://www.cheese-rolling.co.uk/index.htm) and answer the following questions:

a) What parts of the body are usually hurt when cheese-rolling?

b) How many types of aid services attend the festival?

c) What happens with the participants who do not reach the bottom of the hill while cheese-rolling?

d) Has the cheese ever been stopped from rolling?

f) Why was not the 1998 banning successful?

4) The Spring Bank Holiday has arrived. Mike and his friend get to Brockworth by bus. Then they reach the top of Cooper's Hill and make it to the front line to participate in one of the cheese-rolling races.

\section{GRAMMAR:PAST SIMPLE, PAST CONTINUOUS AND PAST PERFECT}

4.1.) Mike wrote an email to his brother describing how he and his friend arrived in Brockworth, how they reached the start line of the race and how the race developed.

Look at this sentence from the email. Check with the grammar rules.

Once the master of ceremonies had escorted the female guest who was going to roll the cheese down the hill, the chase began.

- Use the ____ to talk about consecutive actions in the past.

- Use the ___ to talk about something which happened before the past time we are talking about.

- Use the to describe a longer past action.

[Rules taken from Oxenden, C. \& Latham-Koenig, C. (1999). English File Intermediate. Oxford: Oxford University Press, p. 88]

4.2.) Complete Mike's e-mail. Choose the right verb form.

4.3.) PRACTICE. Put the right verb tense in the following sentences (past simple, past continuous and past perfect).

The event (take place) at Cooper's Hill in Gloucestershire. It (be) spectacular to watch, but several of the competitors (break) an arm or a leg or sprained their ankles. Even one of the spectators (be hit) by a flying cheese and (be taken) to hospital. When I was going to the pub afterwards, it (start) to rain so I ran. As I (enter), my friends (give) me a pint as they (arrive) already and (order) the drinks.

5) Mike tells his girlfriend about his Cheese-Rolling day.

\section{SPEAKING}

Talk to your partner. Describe Mike's day in the Cheese-Rolling festival. Here you have some notes to help you: 
- Date.

- How and when he arrived in Brockworth.

- When he arrived at the bottom of Cooper's Hill.

- When he reached the top of Cooper's Hill.

- How he got on in the cheese race.

- Any resulting injuries he got.

- Imagine you are a friend of Mike's. Tell him your opinion about the Cheese-Rolling festival in general and about what he did.

\section{WRITING}

Have you ever been in another folklore festival in your country? You are going to write an email to an English friend describing your experience.

6.1.) Here you have the email mentioned in exercise 4. Look at its paragraphs and at the highlighted parts.

- Can you notice any colloquial features typical of an informal interaction?

- Are the English conventions for writing an informal email the same as in your mother tongue?

- What about gender differences? Are the conventions in English and your mother tongue the same when the addresser and the addressee are both women or men, or a man and woman?

6.2.) Write your email. Use the following notes to help you:

- Date

- Country

- City/town/village

- What does it consist about?

- What are the origins? Religious or pagan festival?

- Are there any special roles for men and women?

- Is it well-known in your country? In the rest of the world?

- What's your opinion about it? Would you recommend another person from your country or a foreigner to attend it?

Table 2. CPM lesson based on the Cheese-Rolling festival script.

As can be seen, similar to the Task-Based Language Teaching Approach, where "the "natural sequence of events' changes into a 'pedagogically conditioned sequence of events' fully dependent on linguistic needs and skills" (Sánchez, 2004: 54), the pedagogic adaptation of scripts necessarily entails certain divergences or adjustments regarding the original sequence. This can be specially observed in three aspects. 
Firstly, as stated above, a follow-up writing task not included in the real-life sequence has been added so as to a) to revise and consolidate the language studied in the lesson (describing a folklore celebration and recounting its attendance in the past) and b) to study informal email conventions in L2 English and the students' L1.

Secondly, and as mentioned above too, this specific pedagogic adaptation requires the separation of communicative stage 1 in the real-life sequence into two communicative stages in the teaching sequence, with their two corresponding activity sections. If just for the sake of variety and a balanced presentation of contents, I thought that it would be more convenient to have an alternation of skill activities (sections 1 and 3 ) and grammar/functions activities (sections 2 and 4), rather than presenting the listening and reading activities together and immediately followed by the two sections dealing with functions and structures.

Thirdly, communicative stages 3-7 in the real-life sequence regarding the arrival at Cooper's Hill and the actual Cheese-Rolling cannot be exactly transferred to the ELT classroom, where the superseding goal is English language learning. In other words, besides the fact that it would be very difficult and absurd to make students roll down a mountain, the linguistic outcome will be null. Thus such stages need to be adapted as either aural or written receptive texts which recount everything that happens in those stages.

The lesson above offers certain cultural, pedagogic and cognitive advantages that deserve commenting on. In terms of culture, all the activities revolve around the cultural situation (the script for the Cheese-Rolling festival) and they are accordingly ordered following the underlying sequence of actions or script. This reinforces the merging of language along the development of the script in its different stages; for instance, obtaining information about the festival is pedagogically adjusted as a listening and reading activity; deciding to attend the cheese race is linguistically translated as functions for suggesting and agreeing; retelling the experience is transformed as a speaking activity, etc. Students' sociocultural knowledge is developed through the learning of a specific cultural event and the clear highlighting of 'Double Gloucester cheese' as a discrete cultural item in the answer to the second question from exercise 1.1. What is more, learners' intercultural awareness is openly worked upon in accordance with the importance granted to it in the CEFR (2001). This is fulfilled in two different ways. On the one hand, the contrastive rhetoric present in activity 6 (Writing) implies reflection on the formulation and conventions of an informal email in L2 English and the L1; also, exercise 2.1. requires the comparison between L2 English and L1 ways of suggesting and agreeing. On the other hand, students' views and attitudes are overtly triggered and developed by asking their oral opinion about the Cheese-Rolling festival in activity 5, as well as by writing an account of a similar experience in their native countries for an imaginary Englishspeaking friend, where they have to express their related opinions too (section 6). In all, as can be seen, the pedagogical adaptation of scripts through the CPM perfectly integrates cultural and linguistic elements.

Several teaching advantages can also be described. Regarding skills, the four of them are practised throughout the lesson (listening, reading, speaking and writing). Receptive-skill activities (listening and reading in sections 1 and 3) go before production-skill activities (speaking and writing in sections 5 and 6). This is directly related to learning principles dictated by cognitive psychology, as we shall see below. Also, different types of listening and 
reading strategies are worked upon: listening for gist, listening for detail, reading for detail (activities 1.1., 1.2. and 3.2. respectively). Pragmatic functions are covered in section 2, and the formal expression of such functions matches those indicated in the "threshold" level (van Ek and Trim, 1998: 39), which corresponds to the B1 or intermediate level. Linguistic subskills are developed too: grammar (section 4); pronunciation (activity 3.1.) and vocabulary (the lexis belonging to the listening and reading texts and activity 3.1.). Activity 3.1. can be considered revision and expansion of the body parts semantic field, since intermediate students will have surely studied it in previous levels. The language functions and structures are staged following a presentation (activities 2.1. and 4.1.), controlled manipulation and practice (activities 2.2., 4.2. and 4.3.) and final production for the structures (activities 5 and 6). This progression does also correspond to cognitive learning theory (see below).

From a cognitive perspective, this lesson complies with Anderson's model of skill learning: ACT and its more refined latest version ACT-R (Anderson, 1982, 2005; Anderson and Lebiere, 1998; Anderson et al., 2004). It is widely accepted in cognitive psychology (DeKeyser, 1998) and has been applied to SLA and FLT by numerous authors (O'Malley et al., 1987; Johnson, 1994, 1996; DeKeyser, 1997, 1998; Criado, 2008; Criado and Sánchez, in press $\mathrm{a}$, in press b). In this model, declarative knowledge (know-what) precedes the acquisition of procedural knowledge (know-how), which is later automatised. In other words, as applied to language learning, knowledge about the functioning of the linguistic system should precede knowledge of how to use such a system, which also seems to support the notion that production should follow comprehension. This cognitive sequence is reflected in this lesson as receptive work prior to productive work, the explicit focus on form in activities 2.1. and 4.1. before the actual proceduralisation with practice (activities 2.2., 4.2., 4.3.) and final automatisation (sections 5 and 6). Similar to Criado and Sánchez (in press a, in press b), it is acknowledged that even though separate delimitations are made in a single lesson among declarativisation, proceduralisation and automatisation for analytical purposes, such cognitive processes are most probably not attained in a unique lesson. Consequently, there is a constant need for recycling the language studied in later teaching units.

\section{Conclusion}

Traditionally, culture teaching has been almost entirely restricted to lexis and has neglected scripts. However, a complete and coherent intercultural teaching, so much in vogue nowadays, should not only cover lexical units but encompass scripts as well. As explained above, scripts are important exponents of the culture of a particular language community: they involve an event-sequence of a cultural situation relevant to such a community and hence are conveniently proceduralised. Thus my goal in this paper has been to propose the integration of culture and language teaching in ELT by means of the pedagogical adaptation of scripts through the CPM. Such a pedagogical adaptation is not difficult to implement and has been shown a) to comply with essential parameters in FLT, namely, pedagogical, cognitive and, of course, cultural; b) to perfectly transfer the real-life sequence of events within the script to the teaching sequence; c) to completely integrate linguistic elements in the teaching sequence, 
given that linguistic activities of various kinds and nature were designed around the development of a real-life script; d) to cater for the development of sociocultural knowledge and intercultural awareness; e) to sufficiently cover culture without neglecting language in any moment, in accordance with the overruling goal of a FLT class, i.e. to improve language competence.

\section{References}

Almela, Moisés (2006): From Words to Lexical Units: A Corpus-Driven Account of Collocation and Idiomatic Patterning in English and English Spanish. Peter Lang, Frankfurt am Main, Berlin, Bern, Bruxelles, New York, Oxford, Wien.

Anderson, John Robert (1982): Acquisition of Cognitive Skill. Psychological Review 89(4): 369-406. . (2005): Cognitive Psychology and its Implications ( $6^{\text {th }}$ ed.). New York: Worth Publishers.

Anderson, John Robert and Christian Lebiere (1998): The atomic components of thought. Mahwah, NJ: Erlbaum.

Anderson, John Robert, Daniel Bothell, Michael D. Byrne, Scott Douglass, Christian Lebiere and Yulin Qin (2004): An integrated theory of the mind. Psychological Review 111: 1036-1060.

Byram, Michael (1989): Cultural Studies in Foreign Language Education. Clevedon: Multilingual Matters.

. (1997): "Cultural studies and foreign language teaching". In S. Bassnett, ed., Studying British Cultures. An Introduction. London: Routledge, 53-65.

Byram, Michael, Carol Morgan and Colleagues (1994): Teaching-and-Learning Language-andCulture. Clevedon: Multilingual Matters.

Chandler, Daniel (1994): The Sapir-Whorf Hypothesis.

[http://www.aber.ac.uk/media/Documents/short/whorf.html]. [30.06.2004]

Council of Europe (2001): Common European Framework of Reference for Language Learning, Teaching and Assessment. Cambridge: Cambridge University Press.

Criado, Raquel (2008): Patterns of Activity Sequencing in the Teaching of English as a Foreign Language and their Effects on Learning: A Quasi-Experimental Study. Dissertation. University of Murcia, Spain.

[http://www.tesisenred.net/TDR-1021108-094744/index_cs.html]

Criado, Raquel and Aquilino Sánchez (in press a): The Universal Character of the $D E C->P R O$ Cognitive Sequence in Language Learning and Teaching Materials. RESLA 22.

. (in press b): "Cognitive Patterns in the Acquisition of Knowledge and the Sequencing of Activities in the Organization of Teaching Materials." Proceedings of the 32nd AEDEAN International Conference. Palma de Mallorca, 2008.

DeKeyser, Robert (1997): Beyond explicit rule learning: Automatizing second language morphosyntax. Studies in Second Language Acquisition 19(2): 195-211.

. (1998): "Beyond focus on form: Cognitive perspectives on learning and practicing second language grammar". In C. Doughty and J. Williams, eds., Focus on Form in Classroom Second Language Acquisition. Cambridge: Cambridge University Press, 42-63.

Gardner, Dee (2007): "Validating the Construct of Word in Applied Corpus-based Vocabulary Research: A Critical Survey". Applied Linguistics 28(2): 241-265.

Johnson, Keith (1994): Teaching Declarative and Procedural Knowledge”. In M. Bygate, A. Tonkin and E. Williams, eds., Grammar and the Language Teacher. London: Prentice Hall, 121-131. 
. (1996): Language Teaching and Skill Learning. Oxford: Blackwell.

Kramsch, Claire (1993): Context and culture in language teaching. Oxford: Oxford University Press. . (1998): Language and Culture, Oxford: Oxford University Press.

. (2001): "Intercultural Communication". In R. Carter and D. Nunan, eds., The Cambridge

Guide to Teaching English to Speakers of Other Languages. Cambridge: Cambridge University Press, 201-206.

Kramsch, Claire, Albane Cain, and Elizabeth Murphy-Lejeune (1996): "Why should language teachers teach culture?" Language, Culture and Curriculum 9(1): 99-107.

Lado, Robert (1957): Linguistics Across Cultures. Michigan: Ann Arbor.

Macaro, Ernesto (2003): Teaching and Learning a Second Language. London: Continuum.

McDevitt, Barbara (2004). "Negotiating the Syllabus: A win-win Syllabus". ELT Journal 58(1): 3-9.

Oxenden, Clive and Christina Latham-Koenig(1999): English File Pre-Intermediate. Student's Book. Oxford: Oxford University Press.

O'Malley, J. Michael, Anna Uhl Chamot and Carol Walker (1987): Some applications of cognitive theory to second language acquisition. Studies in Second Language Acquisition 9: 287-306.

Popper, Karl (1970): "Normal Science and its Dangers". In I. Lakatos and A. Musgrave, eds., Criticism and the Growth of Knowledge. London: Cambridge University Press, 51-58.

Rumelhart, David E. and Andrew Ortony (1976): The representation of knowledge in memory. In R. C. Anderson, R. J. Spiro and W. E. Montague, eds., Semantic factors in cognition. Hillsdale, NJ: Erlbaum, 99-135.

Sánchez, Aquilino (2001): "Sequencing of Activities and Motivation". In V. Codina Espurz and E. Alcón Soler, eds., Language Learning in the Foreign Language Classroom. Castellón: Universidad Jaume I, 116-132.

. (2004): The Task-based Approach in Language Teaching. IJES 4(1): 39-71.

. (2007): "Y qué significa conocer una palabra?" In M. Martínez Cabeza, N. McLaren and Luis Quereda, eds., Estudios en honor de Rafael Fente Gómez. Granada: Universidad de Granada, 179-195.

Sapir, Edward (1958): Culture, Language and Personality. Ed. D. G. Mandelbaum. Berkeley, CA: University of California Press.

Shank, Robert C. and Robert P. Abelson (1977): Scripts, Plans, Goals, and Understanding. An Inquiry into Human Knowledge Structures. Hillsdale, NJ: Erlbaum.

Van Ek, Jan Ate and John Leslie Melvilla Trim (1998): Threshold 1990. Council of Europe. Cambridge: Cambridge University Press.

Whorf, Benjamin Lee (1956): Language, Thought, and Reality: Selected Writings of Benjamin Lee Whorf. Ed. J. B. Carroll. Cambridge: MIT Press.

\section{Appendix}

a) LISTENING TEXT (section 1):

Hello, this is Radio Gloucestershire. Today we're going to witness one of the most unique competitions in the world. The Cooper's Hill Cheese-Rolling is an annual event held on the Spring Bank Holiday at Cooper's Hill, near Gloucester in the Cotswolds region of England. It is traditionally by and for the people of Brockworth - the local village, but now people from over the world take part. The event takes its name from the hill on which it occurs.

In this annual custom a large round Double Gloucester cheese is set off rolling down Cooper's Hill, near Brockworth (Gloucestershire). People chase after it - themselves running, tumbling, 
rolling, and bouncing - and the one who gets to the bottom first wins the cheese. There are several cheeses, and therefore several races, including one for females only.

Accurate information is hard to come by, but the tradition is at least 200 years old. Suggestions have been made that the event may either date back to Roman times or have been a pagan healing ritual, but there is no evidence for this.

If you want to participate this year, you just need to go to Brockworth and get to the front line in Cooper's Hill. You don't need to register and there is no cost for anyone except for parking (five pounds), which is used to pay for the organisation of the event.

b) BODY PICTURE (exercise 3.1.). From A. Sánchez (2006): En Directo. Libro del alumno. Nivel medio. Madrid: SGEL S.A., p. 12.

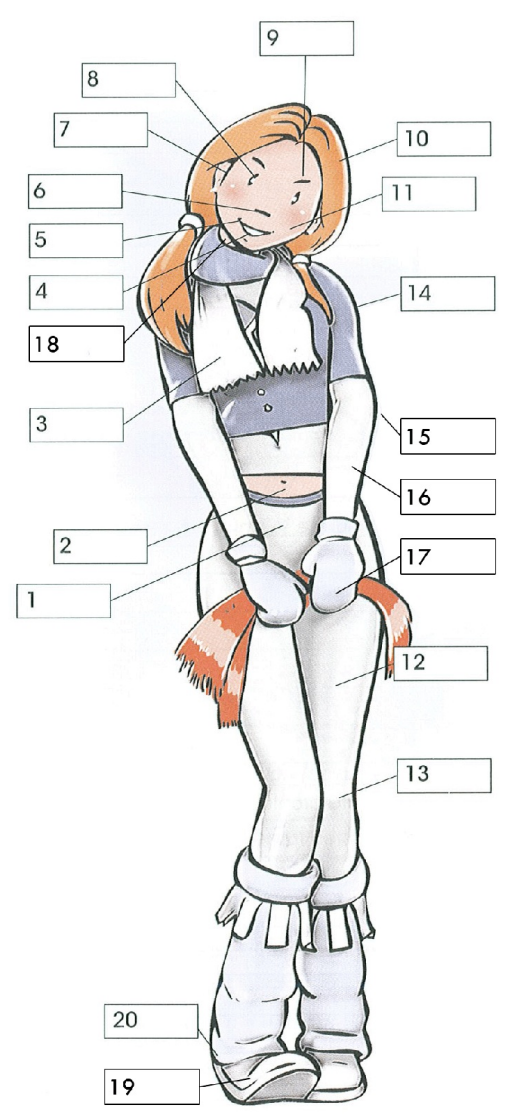

c) READING TEXT (section 3):

Are you thinking about taking part in the Cheese-Rolling festival next year? Well, if so, you might like to know if Cheese-Rolling is safe! It is not, I'm afraid... What exactly can happen to you?

Due to the steepness and uneven surface of the hill there are usually a number of injuries, ranging from sprained ankles to broken bones and concussions. A first aid service is provided by the local St. John Ambulance at the bottom of the hill, with a volunteer rescue group on hand to carry down any casualties who do not end up at the bottom through gravity. A number of ambulances will 
attend the event, since there always are participants who require hospital treatment.

But even despite this serious risk for the participants' health, the festival has enjoyed a lot of popularity. In 1998, when the custom was banned by the local authority because of safety fears, afew dedicated traditionalists came out early on the day to chase one cheese down the hill and thus 'keep the tradition going' (Daily Telegraph (26 May 1998), 3); it resumed officially in 1999.

d) INFORMAL EMAIL (sections 4 and 6):

\section{Hi, Tom!}

How are you doing there in DC??? I really hope you're well, it's been ages since I last heard from you!

Well, I'm dropping you a few lines to tell you about my last crazy adventure... I went cheeserolling!!

I listened to a radio-programme announcing this year's event and I thought it was a great opportunity to have fun, don't you reckon?

I [(a) persuaded; b) was persuading; c) had persuaded] my flatmates to come with me, Paul and David. And first of all, we had to get suitably dressed for the event, hey! Both me and Paul [a) sorted out; b) were sorting out; c) had sorted out] some clothes the night before (t-shirts that were too big at the start of the university, and now were too small...). You don't want to know what we looked like, especially after we (a) cheese-rolled; b) were cheese-rolling; c) had cheese-rolled]!

It [a) rained; b) was raining; c) had rained] so hard on the big day, you can't imagine! We were soaked through by the time we [a) arrived; b) were arriving; c) had arrived] at the bus stop for Brockworth, where the people [a) chased; $b$ ) were chasing; $c$ ) had chased] the cheese. The bad thing is that the bus [a) was, b) was being; c) had been] so late then we [a) had to walk; b) were having to walk; c) had had to walk] until Cooper's Hill, where the people [a) chase; b) were chasing; c) had chased] the cheese! So we [a) battled; b) were battling; c) had battled] through the mud and finally [a) reached; b) were reaching; c) had reached] the bottom of Cooper's Hill. And there, wow, people [a) slide down; b) were sliding down; had slide down] all over the place. We [a) arrived; b) were arriving; c) had arrived] in time to witness the end of the fourth race, and we desperately wanted to be on time for the final race. Yes, we [a) spent; $b$ ) were spending; c) had spent] two hours getting there and we were going to throw ourselves down a hill, cheese or not!

Anyway, we [a) pushed; b) were pushing; c) had pushed] and we finally [a) crawled; b) were crawling; c) had crawled] to the top of the hill and [a) made; b) were making; c) had made] it to the front. Once the master of ceremonies had escorted the female guest who was going to roll the cheese down the hill, the chase began.

I don't particularly remember anything from the race except that it was too muddy and too fast and that I soon lost my balance. None of us [a) received; b) were receiving; c) had received] any major injuries, only a bit of a concussion, contrary to some of the other participants! So yes, we [a) went cheese-rolling; b) were going cheese-rolling; c) had cheese-rolled] and we [a) survived; b) were surviving; c) had survived]!

Well, that's all from me now. Please take care of yourself and do write back - I'd love to hear your news.

\section{Look after yourself, MIKE}

P.S. I've attached some pics of the event. Don't laugh, please! 